ARTICLE

Check for updates

\title{
Proximity to coal-fired power plants and neurobehavioral symptoms in children
}

\author{
Charlie H. Zhang ${ }^{1}$, Lonnie Sears ${ }^{2}$, John V. Myers ${ }^{3}$, Guy N. Brock ${ }^{3}$, Clara G. Sears ${ }^{4}$ and Kristina M. Zierold ${ }^{5 凶}$ \\ (c) The Author(s), under exclusive licence to Springer Nature America, Inc. 2021
}

\begin{abstract}
BACKGROUND: Coal-fired power plants are a major source of air pollution that can impact children's health. Limited research has explored if proximity to coal-fired power plants contributes to children's neurobehavioral disorders.

OBJECTIVE: This community-based study collected primary data to investigate the relationships of residential proximity to power plants and neurobehavioral problems in children.

METHODS: 235 participants aged 6-14 years who lived within 10 miles of two power plants were recruited. Exposure to particulate matter $\leq 10 \mu \mathrm{m}\left(\mathrm{PM}_{10}\right)$ was measured in children's homes using personal modular impactors. Neurobehavioral symptoms were assessed using the Child Behavior Checklist (CBCL). Multiple regression models were performed to test the hypothesized associations between proximity/exposure and neurobehavioral symptoms. Geospatial statistical methods were used to map the spatial patterns of exposure and neurobehavioral symptoms.

RESULTS: A small proportion of the variations of neurobehavioral problems (social problems, affective problems, and anxiety problems) were explained by the regression models in which distance to power plants, traffic proximity, and neighborhood poverty was statistically associated with the neurobehavioral health outcomes. Statistically significant hot spots of participants who had elevated levels of attention deficit hyperactivity disorder, anxiety, and social problems were observed in the vicinity of the two power plants.

SIGNIFICANCE: Results of this study suggest an adverse impact of proximity to power plants on children's neurobehavioral health. Although coal-fired power plants are being phased out in the US, health concern about exposure from coal ash storage facilities remains. Furthermore, other countries in the world are increasing coal use and generating millions of tons of pollutants and coal ash. Findings from this study can inform public health policies to reduce children's risk of neurobehavioral symptoms in relation to proximity to power plants.
\end{abstract}

Keywords: Proximity to coal-fired power plants; $\mathrm{PM}_{10}$ exposure; Children; Neurobehavioral symptoms; Hot spots

Journal of Exposure Science \& Environmental Epidemiology (2022) 32:124-134; https://doi.org/10.1038/s41370-021-00369-7

\section{INTRODUCTION}

Coal-fired power plants that are a major source of toxic air pollution including $\mathrm{SO}_{2}, \mathrm{NOx}$, particulate matter $\leq 10 \mu \mathrm{m}\left(\mathrm{PM}_{10}\right)$, and particulate matter $\leq 2.5\left(\mathrm{PM}_{2.5}\right)$ can adversely impact residents' health in the nearby communities [1, 2]. In addition to pollutants that are emitted from the stack of power plants, communities may be exposed to coal ash, which is a waste product that is generated during the combustion of coal. Coal ash is comprised of fly ash, bottom ash, boiler slag, and flue gas desulfurization material [3] that contains several neurotoxic components, including heavy metal(loid)s, dioxins, and PAHs [4-8]. Fly ash, which is the component that is generated in the greatest quantities, consists of spherical particles with diameters that range from $0.1 \mu \mathrm{m}$ to $>100 \mu \mathrm{m}$. Fly ash is composed of silicon, iron, aluminum, and oxygen, but may also contain neurotoxic metal(loid)s such as arsenic, mercury, and lead at trace levels $[9,10]$.
Fly ash that is captured in air pollution control devices is usually stored in landfills and surface impoundments on the property of the power plant. In the United States, there are over 1,400 landfills and surface impoundments, which are frequently placed near lowincome residential communities [11-14]. These storage facilities may give rise to fugitive dust that exceeds the National Ambient Air Quality Standards for fine particulate matter and hence affects the health of nearby residents $[15,16]$. For example, Mueller et al. found that fugitive dust $\mathrm{PM}_{10}$ concentrations in the vicinity of coal fly ash storage sites frequently exceed $60 \mu \mathrm{g} / \mathrm{m}$ [17]. Research has also suggested that fly ash can be blown by wind to as far as 30 $\mathrm{km}$ away from coal-fired power plants [18, 19]. Dinis et al. [20] estimated population exposure to radionuclides emitted from coal-fired power plants in communities within a $20 \mathrm{~km}$ radius. Studies using source apportionment analysis methods have identified a linkage between coal fly ash and the concentration

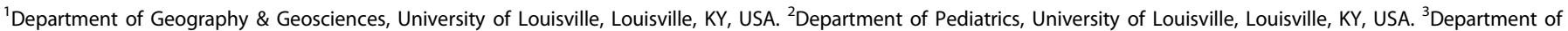

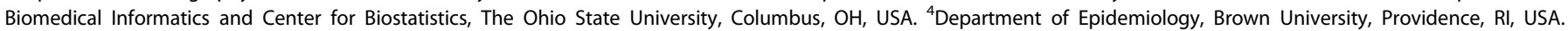

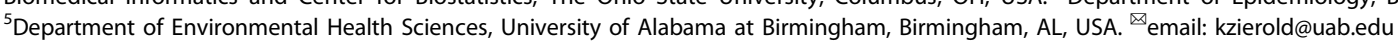


of ambient $\mathrm{PM}_{10}$ near coal-burning power plants [21-24]. Taken together, stack emissions and landfill/surface impoundment emissions can release high levels of $\mathrm{PM}_{10}$ within communities residing in proximity to coal-fired power plants.

Small particles from coal-fired power plants and storage sites can reach the brain indirectly through the lungs and bloodstream or directly through the olfactory bulb [25] causing neurobehavioral symptoms [26]. Substantial research has suggested that compared with adults, children are more vulnerable to the effects of air pollution. Children living near power plants may be at risk for poor health outcomes. Researchers have shown that compared with children not living near power plants, children living in proximity to coal-fired power plants experience increased respiratory effects [27-30]. However, limited studies have investigated how residential proximity to coal-fired power plants contributes to children's neurobehavioral disorders [31-33]. A recent study reported that children who resided near coal-fired power plants with coal ash storage facilities and were exposed to greater $\mathrm{PM}_{10}$ concentrations indoors. Meanwhile, those children had a higher risk of commission errors on the continuous performance and selective attention tests, compared with children exposed to lower concentrations of $\mathrm{PM}_{10}$ [31]. Coal ash may contain several neurotoxins found to impact cognitive ability and behavior in children including manganese [34], arsenic [35], chromium [36], lead [37], mercury [38], and cadmium [39, 40].

Among existing studies that have explored the impact of emissions from power plants on children's health, scholars have primarily measured residential proximity to polluting sources using aggregated data (e.g., zip or postal codes, and census tracts), which may be subject to ecological fallacy [11, 29, 41-43]. Using individual-level observations for a carefully selected sample can provide more convincing information regarding the nexus between proximity to power plants and neurobehavioral symptoms. Furthermore, prior studies have mainly relied on the use of global statistical methods that capture only general characteristics of the entire data set or all observations. Latest research has suggested the rationale of using local spatial statistical approaches (e.g., hot spot analysis) that can help reveal detailed spatial disparities in epidemiological or health problems within a study area [44-46].

This article examined the relationships between neurobehavioral symptoms in children and their proximity to coal-fired power plants with coal ash storage facilities, which are the major sources of air pollution to nearby communities. It is hypothesized that participants who resided in the vicinity of the two power plants have higher levels of $\mathrm{PM}_{10}$ exposure and higher risks of neurobehavioral problems and their magnitude decreases with distance. We used linear and nonlinear regression methods to investigate factors associated with neurobehavioral symptoms and employed global and local geospatial statistical methods to explore the geographical disparities in neurobehavioral symptoms among the children being surveyed. The data for this paper comes from a larger community-based study that is exploring the relationship between coal ash exposure and children's health $[31,47]$. This is the first study to map hot spots of neurobehavioral symptoms in children in the vicinity of coal-fired power plants located in a large urban community.

\section{MATERIALS AND METHODS}

\section{Power plants and storage facilities}

Both power plants-Cane Run and Mill Creek-are in Louisville, Kentucky, USA, a river city located on the south bank of the Ohio River, which divides the state of Kentucky and Indiana (Fig. 1). Their latitude and longitude coordinates are as following: Cane Run (38.175573N, 85.894129 W) and Mill Creek (38.0441N, 85.907309W). The Cane Run Generating Station was built in the 1950s and by 1969 operated a total of six units with a total generating capacity of $943 \mathrm{MW}$ [48]. Cane Run burnt over one million tons of high sulfur coal each year when operating as a coal-fired plant. This plant has a 110-acre coal ash landfill and a surface impoundment with multiple ponds that store coal ash. The main pond is 52 acres in size and received a high hazard rating by the Environmental Protection Agency (EPA) indicating that collapse of the pond may lead to loss of life or major damage to buildings or utilities [49]. In 2015, the Cane Run power plant began operating using natural gas, and the landfill and pond were capped by August 2017.

The Mill Creek Generating Station sits on 544 acres of land, along the Ohio River downstream from Cane Run. It is Kentucky Utilities' largest coalfired power plant and began operating in the early 1970s [50]. It burns $\sim 4.8$ million tons of coal a year and has a generating capacity of $1465 \mathrm{MW}$. There is one large landfill onsite and five surface impoundments on the property. The main pond that holds coal ash is rated as high hazard by the EPA [51]. The two power plants have been the center of neighborhood concern for years. Residents claim coal ash blows into their homes, yards, and cars, and is made airborne by wind and storms and when trucks drive around or move piles on the landfill and into the surface impoundments.

\section{Spatial sampling strategy and study participants}

For this research, we focused on communities on the Kentucky side, which are densely populated urban areas while the Indiana side separated by the Ohio River is sparsely populated. To increase the accuracy and consistency of spatial sampling, following a practice similar to Allpress et al. [52], we used a quadrat-buffer reference system to guide our recruitment endeavors. The straight-line that connects the two power plants and the mid-point between them were used to create four quadrants and five distance buffers (i.e., 2-mile interval), which split the study area into 20 sampling units (i.e., A1-A5, B1-B5, C1-C5, and D1-D5 in Fig. 1). These 20 sampling units cover an area of 157 square miles encompassing the southwestern portions of Jefferson and northern Bullitt counties in Kentucky [47]. Small portions of A4 and A5 (i.e., small areas located on the north side of the Ohio River) were excluded for sampling because they fall in the state of Indiana.

Recruitment began in fall 2015 and continued until COVID-19 ended home visits in March of 2020. The research team implemented a mixture of recruitment strategies to enroll children who were eligible for this project, including door-to-door flyer distribution, placing flyers in public places, mailing of letters and flyers, media broadcasting, local government outreach, and snowball sampling. University of Louisville (UofL) and University of Alabama Birmingham at Birmingham (UAB) have approved all study protocols and documents (i.e., UofL IRB\#:14.1069 and UAB IRB\#:300003807, respectively).

Participants for this study $(N=235)$ consisted of children aged 6-14 years old and one of their parents/guardians. This age group was chosen based on the ability to utilize the same neurobehavioral measures to assess cognitive ability, attention, and behavior. Parental consent and child assent were obtained before data collection began. All the 235 participants were successfully geocoded based on their residential addresses using geographic information systems and the Topologically Integrated Geographic Encoding and Referencing System database provided by the U.S. Census Bureau. The participants were recruited from more than 12 zip codes encompassing homes in subdivisions, single-standing homes, apartment complexes, and mobile home parks. In order to avoid the bias introduced by the inclusion of multiple children who reside in the same address (i.e., siblings) with the same potential exposure, only one participant was recruited from each household. The children enrolled are predominately white $(n=176,75 \%)$, followed by Black or African American $(n=31,13 \%)$ and other ethnic groups $(n=28,12 \%)$. There are slightly more males ( $n=129,55 \%)$ than females $(n=106,45 \%)$. The median age of the population is 11 years old. The age data were not normally distributed, so the Wilcoxon test was used to test the difference in median age between males and females. There is no significant difference between the median age of males (11) and females (10) $(p=0.34)$.

According to 2015 American Community Survey data, 28\% of children ages 5-14 years lived below the poverty level [53]. Focus group research and results from a community survey, reported that parents of children living near one coal-fired power plant with coal ash storage facilities were more likely to state that their children had neurobehavioral symptoms and disorders (e.g., ADHD)), compared with parents of children not living near coal-fired power plants [54, 55]. 


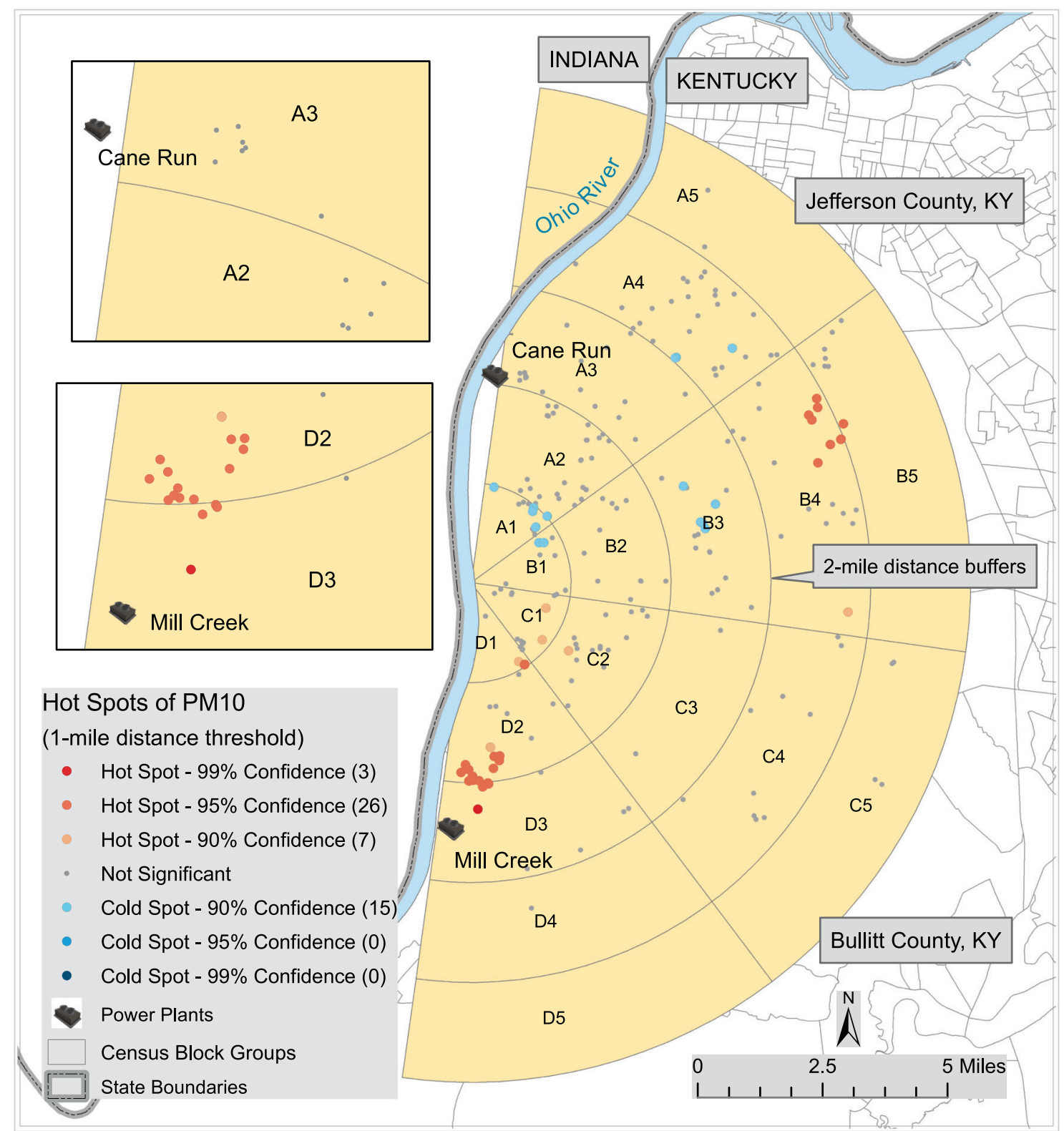

Fig. 1 Hot Spots of PM10 Using One-Mile Buffer. Getis-Ord $G_{i}^{*}$ analysis of hot spots and cold spots of indoor PM 10 readings with data collected at 235 children's homes in west Louisville, KY. Combinations of letters and numbers (e.g., A1, B5, etc.) labeled on the map represent quadrant and distance buffer coordinates that have been used for sampling and recruiting participants.

\section{Measures of exposure and neurobehavioral problems}

Measure of exposure. The magnitude of exposure to air pollution was measured in two ways-proximity to power plants from each participant's residence and indoor concentration of $\mathrm{PM}_{10}$. A distance-based proximity measure is helpful because it provides an unvarying objective indicator of exposure to environmental risks that gradually decreases as distance increases. The Euclidean distance tool in ArcGIS 10.7 was used first to calculate the straight-line distance from participants' residence to the nearest power plant. A maximum of ten miles was then used to demarcate the limit of child exposure metric to power plants following a practice used by prior studies $[56,57]$.

Whereas the distance-based proximity measure is helpful, using distance alone cannot provide direct estimation of the magnitude of exposure that validates a link between toxic emissions from coal-fired power plants and children's neurobehavioral symptoms in the nearby neighborhoods. Supplementing the distance measure, a pollutant-based exposure indicator (i.e., $\mathrm{PM}_{10}$ ) allows us to better understand the adverse health effects of coal ash blown up from storage facilities of power plants that can easily infiltrate into people's homes and yards by wind and storms. It is rational to use indoor $\mathrm{PM}_{10}$ as a proxy measure of air pollution emitted from nearby coal-fired power plants that can travel a long distance and prior research has suggested air pollutants from coal-fired power plants contribute to ambient $\mathrm{PM}_{10}[21,58]$. Moreover, scholars have suggested a strong correlation exists between indoor and outdoor levels of particular matter $[24,59,60]$ and indoor air quality is largely impacted by outdoor pollution, other home characteristics, and occupant behaviors [61, 62].

$\mathrm{PM}_{10}$ samples were taken for 1-week inside the children's homes using personal modular impactors (PMIs) with polycarbonate filters. The PMls were placed $\sim 1.5 \mathrm{~m}$ above the ground, to represent the breathing zone of a child and away from ventilation systems, fireplaces, and windows. During the weeklong $\mathrm{PM}_{10}$ sampling, smoking parents were asked to smoke outside the home to prohibit bias introduced to the measure of indoor $\mathrm{PM}_{10}$. During the study period, mean annual average outdoor $\mathrm{PM}_{10}$ concentrations did not change dramatically and were measured by monitoring stations of the Jefferson County, Air 
Table 1. Descriptive statistics of dependent and independent variables $(n=235)$.

\begin{tabular}{|c|c|c|c|c|}
\hline Variables & Mean & Standard. Deviation & Minimum & Maximum \\
\hline Age (Years) & 10.757 & 2.529 & 6.00 & 14.00 \\
\hline Gender $($ Female $=1$, male $=0$ ) & \multicolumn{4}{|c|}{ Female: 106 (45.1\%); Male: 129 (54.9) } \\
\hline Ethnicity (Non-white $=1$, white $=0$ ) & \multicolumn{4}{|c|}{ White: 176 (74.9\%); Minorities: 59 (25.1\%) } \\
\hline Distance to nearest power plant (miles) & 4.116 & 1.971 & 0.519 & 9.463 \\
\hline $\mathrm{PM}_{10}\left(\mu \mathrm{g} / \mathrm{m}^{3}\right)$ & 22.316 & 17.508 & 3.83 & 164 \\
\hline Traffic proximity (1000 cars $/ \mathrm{m})$ & 0.374 & 0.821 & 0 & 9.853 \\
\hline Anxiety problems (ANP) & 55.298 & 7.088 & 50 & 78 \\
\hline Attention-deficit and hyperactivity disorder (ADHD) & 55.851 & 7.604 & 50 & 80 \\
\hline Conduct problems (CP) & 53.728 & 6.380 & 50 & 87 \\
\hline Social problems (SP) & 54.826 & 7.107 & 50 & 87 \\
\hline
\end{tabular}

Pollution Control District. The $\mathrm{PM}_{10}$ concentrations were $17.5 \mu \mathrm{g} / \mathrm{m}^{3}$ (2015), $15.4 \mu \mathrm{g} / \mathrm{m}^{3}$ (2016), $16.5 \mu \mathrm{g} / \mathrm{m}^{3}$ (2017), $17.5 \mu \mathrm{g} / \mathrm{m}^{3}$ (2018), $18.1 \mu \mathrm{g} / \mathrm{m}^{3}$ (2019), and $17.5 \mu \mathrm{g} / \mathrm{m}^{3}$ (2020).

Measure of neurobehavioral problem. Using the Child Behavior Checklist $(\mathrm{CBCL})$, we collected data for six neurobehavioral scales including affective problems, anxiety problems, attention deficit, and hyperactivity disorder (ADHD) problems, conduct problems, social problems, and thought problems [63]. The $C B C L$ is a widely used parent-completed behavior checklist that compares child behavior patterns to age and gender norms and provides a $t$-score that ranges from 50 to 100 . The primary caregiver for the child completed the behavior checklist and it was scored using $\mathrm{CBCL}$ software. The mean of each $\mathrm{CBCL}$ scale is $50(\mathrm{SD}=10)$ that indicates normal behavior. A $t$-score of 60 indicates borderline significant behavior problem and a score of 70 is two standard deviations above the mean for the sample and indicates a clinically significant behavior problem.

\section{Multiple regression analysis of the association between exposure and health measures}

Multiple linear regression methods were used to investigate the associations between the $t$-score from each CBCL problem behavior scale and proximity to power plants and intensity of $\mathrm{PM}_{10}$. Children residing closer to any of the two power plants and their affiliated coal ash storage facilities are expected to have increased behavior problems, compared to their counterparts living farther away. Likewise, a positive relationship was expected between exposure to $\mathrm{PM}_{10}$ and participants' neurobehavioral symptoms. It was also hypothesized that non-whites (i.e., blacks and other minorities) and participants living in poor neighborhoods experienced higher levels of neurobehavioral problems. Each of the six neurobehavioral symptoms was used as the dependent variable, respectively.

Exposure measures including straight-line distance to the closest power plant, indoor $\mathrm{PM}_{10}$, and traffic proximity were used as the major independent variables. Obtained from the Environmental Justice database collected by the EPA, traffic proximity measures the average annual daily traffic at major roads within $500 \mathrm{~m}$ from each block group and then divided by the distance to the roads (in meters). Prior research has explored the impact of exposure to traffic-related air pollution on children's health in urban communities [64,65]. We also controlled the effects of participants' personal characteristics (i.e., age, gender, ethnicity) and neighborhood-level poverty rates, which were obtained from the 2012 to 2016 American Community Survey (ACS) 5-year estimates for census block groups. Gender and ethnicity were coded as dummy variables with female (1) and male (0); non-white (1), and white (0).

In addition to multiple linear regression models, we also applied generalized additive models (GAMs) and Tobit models to assess if nonlinear relationships existed between the $C B C L$ outcomes and the independent variables $[66,67]$. GAMs were used to assess the significance of spline terms for continuous variables. If the terms were significant in a GAM, then a Tobit model containing a spline term was fit and compared against a Tobit model without the spline term using ANOVA. The model containing the spline term was selected given a statistically significant difference existed between models.
Mapping hot spots of $\mathrm{PM}_{10}$ and children's health conditions

To explore if proximity and exposure to air pollutants emitted from power plants and neurobehavioral symptoms had a spatially clustered distribution across the study area, the High/Low Clustering (Getis-Ord General G) statistic, a global spatial statistical method that measures the degree of clustering for either high values or low values, was used in this study [68]. The Getis-Ord General $G$ tool calculates outputs including observed General $G$ statistic, its $z$ score, and $p$ value, which allow analysts to determine the degree of spatial autocorrelation or dependence across a spatial data set (e.g., $\mathrm{PM}_{10}$ or a problem behavior) in comparison to a random distribution. One strength of the Getis-Ord General $G$ statistic is that it allows researchers to differentiate high-value clustering from lowvalue clustering, thus enabling us to diagnose the spatial concentration of elevated levels of $\mathrm{PM}_{10}$ and children's neurobehavioral symptoms surrounding the two power plants under study.

While the above-mentioned High/Low Clustering analysis is helpful, it provides only an overall diagnosis of the magnitude of spatial clustering for a given spatial distribution such as $\mathrm{PM}_{10}[69,70]$. Complementing global spatial clustering analysis, the Hot Spot Analysis (Getis-Ord $\mathrm{G}_{\mathrm{i}}^{*}$ ) tool, a local spatial statistical method, allows us to map spatial clusters of high values (hot spots) and low values (cold spots) within a study area [46]. A distance threshold is needed to define the spatial context or neighborhood based on which local Getis-Ord $\mathrm{G}_{i}{ }^{*}$ values are calculated for each feature in the data set. Likewise, the statistical significance of hot spots can be determined by checking $z$ scores and $p$ values affiliated with the Getis-Ord $G_{i}^{*}$ output for each feature. The Getis-Ord $G_{i}{ }^{*}$ statistic evaluates each feature's attribute value within the context of its neighborhood to identify spatially clustering hot spots of high values or cold spots of low values in comparison to the average of the entire data set. We used 1-mile distance buffer in the initial global and local hot spot analysis and then conducted a sensitivity analysis using two different distance thresholds (i.e., 0.5 -mile and 2-mile) to evaluate if the results were responsive to the choice of neighborhood settings.

\section{RESULTS}

Multiple regression

Descriptive statistics for the exposure and health outcome variables are presented in Table 1 . Considerable variations of indoor exposure to $\mathrm{PM}_{10}$ (ranging from 3.83 to $164 \mu \mathrm{g} / \mathrm{m}^{3}$ ) were observed from the 235 participants. Indoor $\mathrm{PM}_{10}$ concentrations did not differ by sex $\left(\right.$ male $=18 \mu \mathrm{g} / \mathrm{m}^{3}$, female $=18 \mu \mathrm{g} / \mathrm{m}^{3}$ ). However, children aged 6-10 had higher indoor concentrations of $\mathrm{PM}_{10}\left(18.7 \mu \mathrm{g} / \mathrm{m}^{3}\right)$ compared with children aged 11-14 $(17.1 \mu \mathrm{g} /$ $\left.\mathrm{m}^{3}\right)(p=0.019)$. Disparities in the six measures of neurobehavioral symptoms were also noteworthy with conduct problems and social problems having the largest ranges of variations (i.e., 50-87).

The results of multiple regression analyses showed mixed findings (Table 2). No statistically significant association was observed between personal characteristics (i.e., age and sex) and any of the six neurobehavioral symptoms. It is noteworthy that 
Table 2. Multiple linear regression results of six types of neurobehavioral problems $(n=235)$.

\begin{tabular}{|c|c|c|c|c|c|c|}
\hline \multirow[t]{2}{*}{ Variables } & \multicolumn{6}{|c|}{ Regression models } \\
\hline & AP & ANP & ADHD & CP & SP & TP \\
\hline Constant & $52.487^{* * *}$ & $56.655^{* * *}$ & $27.223^{* * *}$ & $56.277^{* * *}$ & $57.264^{* * *}$ & $55.101^{* * *}$ \\
\hline Gender $($ Female $=1$, male $=0$ ) & -0101 & -1.644 & -1.078 & -0.973 & -0.717 & -0.357 \\
\hline Ethnicity $($ Non - white $=1$, white $=0$ ) & -1.608 & -1.908 & -1.935 & -0.816 & -1.604 & -0.808 \\
\hline Log value of $\mathrm{PM}_{10}\left(\mu \mathrm{g} / \mathrm{m}^{3}\right)$ & 0.089 & 0.646 & 0.631 & 0.127 & 0.287 & -0.797 \\
\hline Traffic proximity (1000 cars/m) & $1.331^{* *}$ & $1.253^{* *}$ & 0.972 & -0.022 & $1.444^{* *}$ & $1.319^{* *}$ \\
\hline Neighborhood poverty (\%) & $0.078^{*}$ & $0.072^{*}$ & 0.040 & 0.056 & 0.065 & $0.087^{*}$ \\
\hline Adjusted R Squared & 0.035 & 0.045 & 0.011 & -0.008 & 0.068 & 0.013 \\
\hline
\end{tabular}

Variance inflation factor (VIF) values for all independent variables in each model had values lower than 1.1, indicating multicollinearity is not of concern. $A P$ affective problems, $A N P$ anxiety problems, $A D H D$ attention-deficit and hyperactivity disorder, $C P$ conduct problems, $S P$ social problems, $T P$ thought problems.

*Significance level of $0.10 ;{ }^{* *}$ significance level of $0.05 ;{ }^{* * *}$ significance level of 0.01

contrary to our expectation and the prevailing environmental justice literature $[11,71]$, non-white participants showed negative signs (i.e., non-white participants had lower values of the neurobehavioral measures than their white counterparts in general) in all six models although statistically insignificant. The main exposure measure-log $\mathrm{PM}_{10}$-showed positive signs as expected for all outcomes (except thought problems) but was not statistically associated with any of the six neurobehavioral measures. Nearest distance to a power plant showed significant and negative regression coefficients with four neurobehavioral symptoms: affective problems, anxiety problems, ADHD, and social problems. The effect of traffic proximity was statistically significant and positive in the models for affective problems, anxiety problems, social problems, and thought problems. Neighborhood-level poverty rate showed consistent positive signs with all six neurobehavioral symptoms but was statistically significant only in models for affective problems, anxiety problems, and thought problems. Regarding model performance, the model for social problems explained about $7 \%$ of its variance while the model for anxiety and affective problems explained about $5 \%$ and $4 \%$ of their variances, respectively. The regression models for ADHD, thought problems and conduct problems were less helpful.

The results from the GAM nonlinear analysis improved model performance indicated by larger pseudo $R^{2}$ values, which are equivalent of adjusted $R^{2}$ in linear models (Table S1). For example, the Tobit regression models explained nearly $11 \%$ of the variance in anxiety problems (up from $5 \%$ in the linear model) and $9 \%$ of the variations of social problems (up from $7 \%$ in the linear model). Square root of distance to power plant was statistically significant (i.e., linear negative) in relation to anxiety problems, ADHD, and social problems as hypothesized. In contrast, square root of traffic proximity showed positive associations (linear) with affective problems, ADHD, social problems, and thought problems. Furthermore, age was positively associated (linear) with affective problems but had a significant nonlinear association with anxiety problems. The regression coefficients for non-white participants were statistically significant but remained negative in the model for ADHD and social problems, while sex showed a statistically significant and negative association with conduct problem that was consistent with what the literature has suggested $[72,73]$.

Global statistical analysis of the spatial patterns of $\mathrm{PM}_{10}$ and health outcomes

Results of global autocorrelation analysis suggest that $\mathrm{PM}_{10}$ had a spatially clustered distribution (i.e., high values were found together) indicated by statistically significant Getis-Ord General $\mathrm{G}$ statistic (i.e., Observed $G=0.005$ with a $z$-score of 2.808 and $p$ value 0.005 ). Distributions of all the six CBCL behavior scales were not statistically significant, indicating random or dispersed spatial patterns. However, this does not exclude the existence of local clusters across the study area - pockets of high values of exposure and neurobehavioral symptoms remain suspicious given that global clustering patterns were not confirmed.

\section{Hot spot analysis of spatial clustering}

Results of hot spot analysis of $\mathrm{PM}_{10}$ and each of the $\mathrm{CBCL}$ behavior problem scales using 1-mile distance threshold were mapped. Hot spots and cold spots of three significance levels (i.e., 99\%, 95\%, and $90 \%$ ) are displayed in the legend of each map with the numbers in parentheses representing the count of hot spots or cold spots being identified. Whereas hot spots or cold spots are illustrated as single dots on maps, it is noteworthy that a hot spot indicates that a given feature (i.e., participant) along with other adjacent features (e.g., within a 1-mile threshold) had statistically significant higher values in exposure to $\mathrm{PM}_{10}$ or $\mathrm{CBCL}$ diagnoses than the mean for the entire study area, not just the target feature itself, and vice versa for a cold spot.

Consistent with our hypothesis, numerous hot spots of statistically significant high values of $\mathrm{PM}_{10}$ (i.e., 3 at the confidence level of $99 \%, 26$ at the confidence interval of $95 \%$, and 7 at $90 \%$ confidence level) were identified around Mill Creek (Fig. 1). Most hot spots clustered near the Mill Creek power plant can be better viewed in the inset maps. But no hot spots were observed near Cane Run. It is also unclear that two clusters of hot spots were found in the outskirts of the sampling area (i.e., B4 and B5) while several cold spots were highlighted in closer vicinity to the power plant of Cane Run.

Social problems showed the most remarkable spatial clustering encompassing 22 hot spots being at the $99 \%$ confidence level, 6 hot spots being at the $95 \%$ confidence interval, and 2 being at the $90 \%$ level (Fig. 2). More importantly, nearly all the hot spots (i.e., 28 out of 30) were observed in the near vicinity of the two power plants (i.e., $<2$ miles), especially Mill Creek, the plant that is still a coal-fired power station with storage facilities. The inset maps within Fig. 2 allow readers to see discrete locations of individual hot spots, which largely overlapped on top of each other due to close distances between them, in the vicinity of Cane Run and Mill Creek. 19 hot spots (all significant at 99\% level) were found near Mill Creek and 9 hot spots were found near Cane Run. Meanwhile, five cold spots are scattered in the periphery of the sampling area (i.e., B3, B4, and A4 quadrants). 


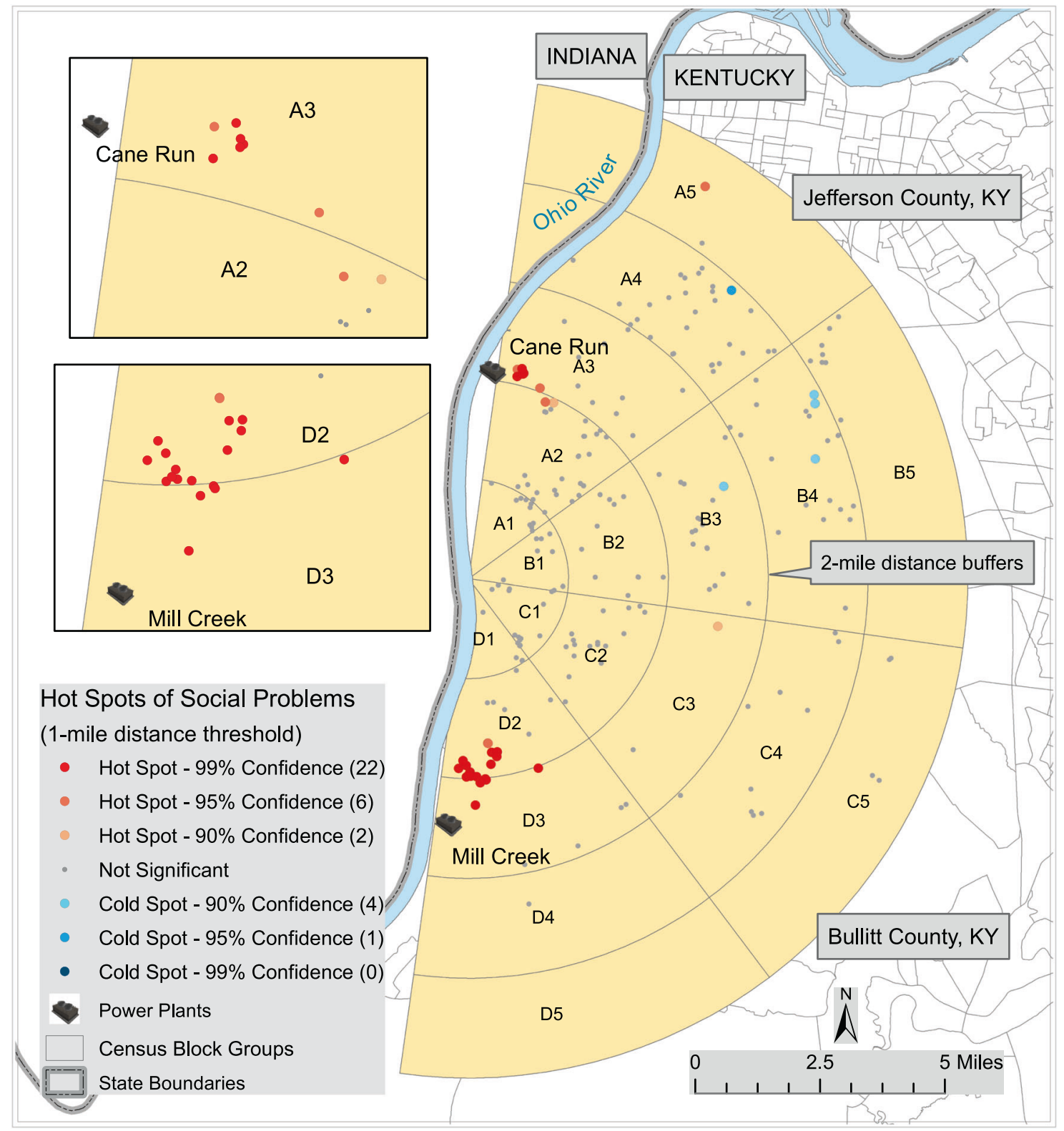

Fig. 2 Hot Spots of Social Problems Using One-Mile Buffer. Getis-Ord $\mathrm{G}_{\mathrm{i}}^{*}$ analysis of hot spots and cold spots of children who have been diagnosed with social problems in west Louisville, $\mathrm{KY}(N=235)$.

For ADHD problems, a total of 29 statistically significant hot spots including 7 being significant at the $95 \%$ confidence interval and 22 at the $90 \%$ level were identified (Fig. 3). It is not random to see congregations of hot spots around the two power plants, especially Mill Creek, which produce both stack emissions of coal ash and fugitive dust emissions from the storage facilities. For anxiety problems, most hot spots were identified near Mill Creek -5 being significant at $95 \%$ confidence level and 17 being significant at $90 \%$ level-while three other hot spots (significant at 0.10 level) were identified in areas that were relatively closer to Cane Run. It is unclear that 21 cold spots were observed in close vicinity to Cane Run and the upper half of the study area. For $\mathrm{CBCL}$ affective and conduct problem scales, only a small number of hot spots were identified across the sampling area but a few hot spots for both problems were found near the Cane Run power plant. Thought problems were the only $\mathrm{CBCL}$ behavior scale with no hot spot identified in the vicinity of any of the two power plants.
Results of sensitivity analysis using a 2-mile distance threshold for social problems were presented in Fig. 4. Whereas the number of hot spots in different confidence levels slightly changed, the spatial patterns of hot spots were similar to our observations from the earlier analyses in which 1-mile cutoff distance was used. The results of hot spots for social problems using 0.5-mile as the distance interval is displayed in Supplementary information (Fig. S1).

\section{DISCUSSION AND CONCLUSION}

This exploratory research investigated the associations of proximity to coal-fired power plants and the prevalence of neurobehavioral symptoms for children using primary data collected from an urban community in the U.S. It extends the existing literature on this topic by applying advanced geospatial statistical methods to the analysis of neurobehavioral health outcomes for individual participants in addition to using classical multiple regression models. Other studies have not incorporated geospatial methods 


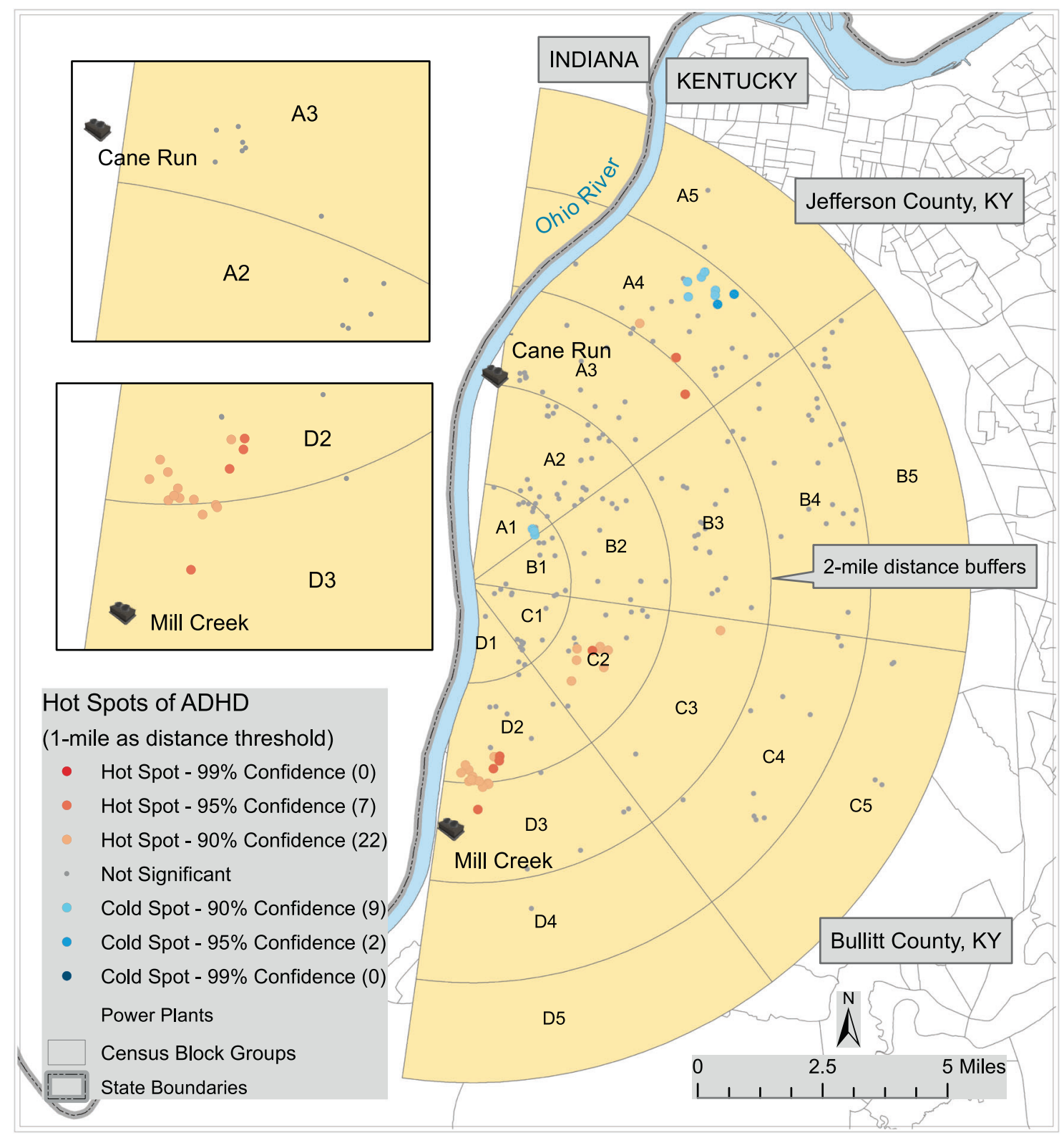

Fig. 3 Hot Spots of Attention Deficit Hyperactivity Disorder (ADHD) Using One- Mile Buffer. Getis-Ord Gi ${ }^{*}$ analysis of hot spots and cold spots of children's attention deficit hyperactivity disorder (ADHD) problem in west Louisville, $\mathrm{KY}(N=235)$.

and are thus overlooking important environmental factors that may influence children's neurobehavioral conditions. Furthermore, although existing research has linked coal-fired power plants with neurodevelopmental conditions such as delayed language, delayed motor skills, and poorer cognitive control [31-33], no research has been conducted among a population of children living within proximity to coal-fired power plants and neurobehavioral symptoms measured by the CBCL.

Multiple regression models (including linear and nonlinear) explained a small proportion of the variations (i.e., ranging from 4 to $11 \%$ ) of the six types of $C B C L$ diagnoses. From the regression models, we have observed mixed findings regarding the associations between $\mathrm{CBCL}$ diagnoses and the independent variables. The primary exposure measure- $\mathrm{PM}_{10}$-was statistically insignificant in all models. This finding is inconsistent with what earlier studies had suggested regarding the adverse impact of proximity to coal-fired power plants on children's health [31, 32].
However, significant and inverse associations were observed between distance to the nearest power plant and four $\mathrm{CBCL}$ diagnoses (i.e., affective problems, anxiety problems, ADHD, and social problems). These findings justified our hypothesis about a distance decay effect of air pollution from the power plants on participants' neurobehavioral health. Likewise, traffic proximity showed significant and positive impact on four $\mathrm{CBCL}$ diagnoses. Neighborhood poverty was significant (and positive) in three linear models, which is consistent with what the prevailing scholarly view that low-income communities are exposed to higher risks of environmental pollution and are more susceptible to poor health. While non-white race was significant in the nonlinear model for ADHD and social problems, it showed a negative sign, which is contrary to our expectation. This could be due to the small proportion of non-white participants (25\%) in our sample.

Given that the global Getis-Ord General G analyses for the six $\mathrm{CBCL}$ outcomes showed statistically insignificant results, the use of 


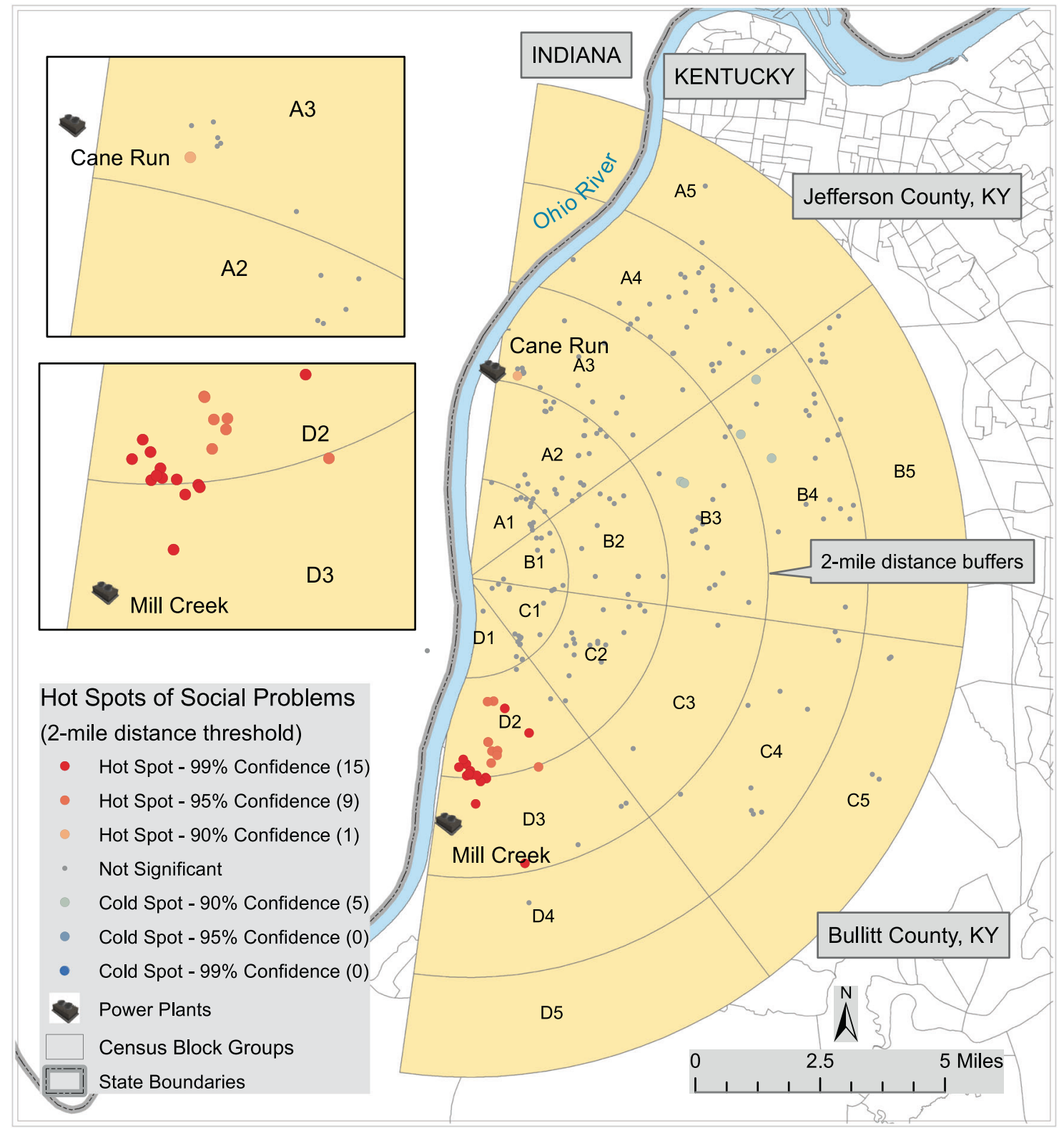

Fig. 4 Sensitivity Analysis of Social Problems Using Two-Mile Buffer. Sensitivity analysis using a 2-mile distance threshold for mapping hot spots and cold spots of children who have been diagnosed with social problems in west Louisville, $\mathrm{KY}(N=235)$.

local cluster analysis enabled us to determine numerous hot spots of $\mathrm{PM}_{10}$ exposure surrounding the two power plants. More important, hot spots of social problems, ADHD, and anxiety problems were identified in the vicinity of the two power plants, especially Mill Creek. Mill Creek is the largest coal-fired power plant in the area and has uncapped coal ash surface impoundments and a landfill. The Cane Run plant converted to natural gas in the summer of 2015, but still had uncapped surface impoundments and a landfill. However, in subsequent years, the storage facilities were capped. This capping process may have reduced exposure to coal ash and therefore may explain why we do not see much clustering or significant effects from these analyses.

Findings from local geospatial statistical analyses shed new light on the spatial disparities or complexities regarding the associations of children's neurobehavioral symptoms and pollutant emissions from power plants across space. The non-random congregation of hot spots of high values of neurobehavioral symptoms in children surrounding the two power plants, which are concealed when using global statistical methods, can be considered partial evidence that supports a positive association of proximity to coal-fired power plants and escalated risks of neurobehavioral problems. Furthermore, our strategy of spatial sampling and recruiting one participant per household excluded the phenomenon of 'false clustering' when analyzing spatial patterns of health outcomes.

There are several strengths of this study that need to be highlighted. First, this was a community-based study, so that we were able to gather a large sample of first-hand data on $\mathrm{PM}_{10}$ in homes of the participants. Prior studies have largely relied on secondary pollution data to investigate health conditions associated with emissions from coal-fired power plants. Furthermore, this research utilized the Child Behavior Checklist or $C B C L$, a widely used measure of neurobehavioral symptoms in children that warranted a systematic diagnosis of symptom severity [74]. To date, no studies have been performed using high-resolution 
primary data of pollutants combined with observed data on neurobehavioral outcomes.

There are also some limitations of this study. Whereas distancebased proximity is helpful to reveal how health risk levels decrease as distance increases from polluting facilities, it is an indirect exposure measure and wind direction can confound this inverse relationship. Future research should consider using more meaningful exposure measures based on the results of source apportionment validation analyses that validate the pollutants originated from nearby coal-fired power plants or coal ash storage facilities $[75,76]$. Recent studies have identified neurotoxic effects of heavy metal(loid)s in fly ash leading to social problems and ADHD in children based on evidence of epigenetic [77] neuroinflammatory [78] mechanisms in the etiology of autism and ADHD. Therefore, collecting additional data on exposure to metal(loid)s and other elements of coal ash emissions from coal-fired power plants $[79,80]$, in future research may provide more convincing evidence that supports the hypothesized relationship of proximity to coal-fired power plants and elevated levels of neurobehavioral symptoms. Also, it is important to control for emissions from other nearby polluting facilities in future research that may also impact the neurobehavioral health condition of children.

Another limitation of this study was that the concentration of $\mathrm{PM}_{10}$ might have changed by season. Although the yearly concentrations did not vary much, seasonality might have had a greater impact. However, when we assessed the difference of $\mathrm{PM}_{10}$ concentrations in the homes of the participants, there was not a significant difference of $\mathrm{PM}_{10}$ by season. The final weakness of this study is that the participants we have recruited may be subject to spatial sampling errors or selection biases. Although we have used multiple recruitment strategies and did not highlight that this study was about neurobehavioral symptoms on recruitment materials, households who are more knowledgeable about coal ash or whose children have health problems may have been more likely to participate $[47,55]$. Therefore, future research should adopt more innovative strategies to improve the geographic and demographic coverage of participants recruitment, thus warranting a more holistic diagnosis of the detrimental impacts of coal ash on children's neurobehavioral symptoms who live in proximity to coal-fired power plants.

A final limitation of this study was that we used a week-long sample of $\mathrm{PM}_{10}$ to represent exposure. Since $\mathrm{PM}_{10}$ levels and composition may change daily and children's exposure may also vary by day, future research that includes daily personal samples and daily area samples would be an improved assessment of exposure.

Despite the weaknesses, the innovative research design - the collection of a large dataset from in situ investigations and the use of local geospatial statistical methods to identify hot spots of neurobehavioral symptoms - and the novel findings of this research help extend the existing studies on spatial health disparities in general and children's neurobehavioral symptoms in particular. Moreover, findings from this study have important policy implications for reducing children's neurobehavioral symptoms in relation to exposure to pollution from coal-fired power plants in urban communities.

\section{REFERENCES}

1. Amster E, Levy CL. Impact of coal-fired power plant emissions on children's health: a systematic review of the epidemiological literature. Int J Environ Res Public Health. 2019;16:2008.

2. Lin C-K, Lin R-T, Chen T, Zigler C, Wei Y, Christiani DC. A global perspective on coal-fired power plants and burden of lung cancer. Environ Health. 2019;18:9.

3. Munawer ME. Human health and environmental impacts of coal combustion and post-combustion wastes. J Sustain Min. 2018;17:87-96.

4. Fernández-Martınez G, Lopez-Vilarino J, López-Mahı $P$, Muniategui-Lorenzo $S$, Prada-Rodrıguez D, Abad E, et al. First assessment of dioxin emissions from coalfired power stations in Spain. Chemosphere. 2004;57:67-71.
5. Lin L-F, Lee W-J, Li H-W, Wang M-S, Chang-Chien G-P. Characterization and inventory of $\mathrm{PCDD} / \mathrm{F}$ emissions from coal-fired power plants and other sources in Taiwan. Chemosphere. 2007;68:1642-9.

6. Wielgosiński G. The reduction of dioxin emissions from the processes of heat and power generation. J Air Waste Manag Assoc. 2011;61:511-26.

7. Buha-Marković JZ, Marinković AD, Nemoda SĐ, Savić JZ. Distribution of PAHs in coal ashes from the thermal power plant and fluidized bed combustion system; estimation of environmental risk of ash disposal. Environ Pollut. 2020;266:115282.

8. Tarafdar A, Sinha A. Polycyclic aromatic hydrocarbons (PAHs) pollution generated from coal-fired thermal power plants: formation mechanism, characterization, and profiling. In: Pollutants from energy sources. Springer, 2019, pp 73-90.

9. Jones T, Brown P, BéruBé K, Wlodarczyk A, Longyi S. The physicochemistry and toxicology of CFA particles. J Toxicol Environ Health Part A. 2010;73:341-54.

10. Zierold KM, Odoh C. A review on fly ash from coal-fired power plants: chemical composition, regulations, and health evidence. Rev Environ Health. 2020; e-pub ahead of print 2020/04/24; https://doi.org/10.1515/reveh-2019-0039.

11. Chakraborty J, Maantay JA, Brender JD. Disproportionate proximity to environmental health hazards: methods, models, and measurement. Am J Public Health. 2011;101:S27-S36.

12. United States Commission on Civil Rights Environmental Justice: Examining the Environmental Protection Agency's compliance and enforcement of Title VI and Executive Order 12898. 2016.

13. Earthjustice (n.d.). The coal ash problem. In, 2020

14. Sierra Club Dangerous waters: America's coal ash crisis. https://coalsierracluborg/ sites/nat-coal/files/report-dangerous-water-coal-ash-crisispdf; Accessed 15 Mar 2021.

15. Environmental Protection Agency. Hazardous and solid waste management system; identification and listing of special wastes; disposal of coal combustion residuals from electric utilities; proposed rule. Fed Reg. 2010;75:35128-264.

16. United States Environmental Protection Agency U.S. Environmental Protection Agency. Inhalation of fugitive dust: a screening assessment of the risks posed by coal combustion waste landfills (draft). 2009.

17. Mueller S, Mao Q, Valente R, Mallard J. Fugitive Emissions from a dry coal fly ash storage pile. In, n.d.

18. Kravchenko J, Lyerly HK. The impact of coal-powered electrical plants and coal ash impoundments on the health of residential communities. North Carol Med J. 2018;79:289-300.

19. Iordanidis A, Buckman J, Triantafyllou AG, Asvesta A. Fly ash-airborne particles from Ptolemais-Kozani area, northern Greece, as determined by ESEM-EDX. Int J Coal Geol. 2008;73:63-73.

20. Dinis ML, Fiúza A, Góis J, Carvalho JMS, Castro ACM. Modeling radionuclides dispersion and deposition downwind of a coal-fired power plant. Procedia Earth Planet Sci. 2014;8:59-63.

21. Feng $Y$, Xue $Y$, Chen $X, W u$ J, Zhu T, Bai Z, et al. Source apportionment of ambient total suspended particulates and coarse particulate matter in urban areas of Jiaozuo, China. J Air Waste Manag Assoc. 2007;57:561-75.

22. Argyropoulos G, Grigoratos T, Voutsinas M, Samara C. Concentrations and source apportionment of PM10 and associated elemental and ionic species in a ligniteburning power generation area of southern Greece. Environ Sci Pollut Res. 2013;20:7214-30.

23. Manousakas M, Diapouli E, Papaefthymiou H, Migliori A, Karydas AG, PadillaAlvarez R, et al. Source apportionment by PMF on elemental concentrations obtained by PIXE analysis of PM10 samples collected at the vicinity of lignite power plants and mines in Megalopolis, Greece. Nucl Instrum Methods Phys Res Sect B: Beam Interact Mater At. 2015;349:114-24.

24. Lee SW. Source profiles of particulate matter emissions from a pilot-scale boiler burning North American coal blends. J Air Waste Manag Assoc. 2001;51:1568-78.

25. Schraufnagel DE. The health effects of ultrafine particles. Exp Mol Med. 2020;52:311-7.

26. Cserbik D, Chen J-C, McConnell R, Berhane K, Sowell ER, Schwartz J, et al. Fine particulate matter exposure during childhood relates to hemispheric-specific differences in brain structure. Environ Int. 2020;143:105933.

27. Goren A, Hellmann S. Changing prevalence of asthma among schoolchildren in Israel. Eur Respir J. 1997;10:2279-84.

28. Peled R, Friger M, Bolotin A, Bibi H, Epstein L, Pilpel D, et al. Fine particles and meteorological conditions are associated with lung function in children with asthma living near two power plants. Public Health. 2005;119:418-25.

29. Rodriguez-Villamizar LA, Rosychuk RJ, Osornio-Vargas A, Villeneuve PJ, Rowe BH. Proximity to two main sources of industrial outdoor air pollution and emergency department visits for childhood asthma in Edmonton, Canada. Can J Public Health. 2017;108:e523-e529.

30. Yogev-Baggio T, Bibi H, Dubnov J, Or-Hen K, Carel R, Portnov BA. Who is affected more by air pollution-sick or healthy? Some evidence from a health survey of schoolchildren living in the vicinity of a coal-fired power plant in Northern Israel. Health Place. 2010;16:399-408. 
31. Sears CG, Sears L, Zierold KM. Sex differences in the association between exposure to indoor particulate matter and cognitive control among children (age 6-14 years) living near coal-fired power plants. Neurotoxicol Teratol. 2020. 106855.

32. Perera F, Li T-Y, Zhou Z-J, Yuan T, Chen Y-H, Qu L, et al. Benefits of reducing prenatal exposure to coal-burning pollutants to children's neurodevelopment in China. Environ Health Perspect. 2008;116:1396-1400.

33. Tang D, Li T-Y, Liu JJ, Zhou Z-J, Yuan T, Chen Y-H, et al. Effects of prenatal exposure to coal-burning pollutants on children's development in China. Environ Health Perspect. 2008;116:674-9.

34. Haynes EN, Sucharew H, Hilbert TJ, Kuhnell P, Spencer A, Newman NC, et al. Impact of air manganese on child neurodevelopment in East Liverpool, Ohio. NeuroToxicology. 2018;64:94-102

35. Tsai S-Y, Chou H-Y, The H-W, Chen C-M, Chen C-J. The effects of chronic arsenic exposure from drinking water on the neurobehavioral development in adolescence. NeuroToxicology. 2003;24:747-53.

36. Caparros-Gonzalez RA, Giménez-Asensio MJ, González-Alzaga B, Aguilar-Garduño C, Lorca-Marín JA, Alguacil J, et al. Childhood chromium exposure and neuropsychological development in children living in two polluted areas in southern Spain. Environ Pollut. 2019;252:1550-60.

37. Needleman HL, Schell A, Bellinger D, Leviton A, Allred EN. The long-term effects of exposure to low doses of lead in childhood. N Engl J Med. 1990;322:83-88.

38. Lozano M, Murcia M, Soler-Blasco R, González L, Iriarte G, Rebagliato M, et al. Exposure to mercury among 9-year-old children and neurobehavioural function. Environ Int. 2021;146:106173.

39. Schoeters G, Hond ED, Zuurbier M, Naginiene R, Van Den Hazel P, Stilianakis N, et al. Cadmium and children: exposure and health effects. Acta Paediatr. 2006;95:50-54.

40. Ciesielski T, Weuve J, Bellinger DC, Schwartz J, Lanphear B, Wright RO. Cadmium exposure and neurodevelopmental outcomes in US children. Environ Health Perspect. 2012;120:758-63.

41. Grineski SE, Collins TW. Geographic and social disparities in exposure to air neurotoxicants at US public schools. Environ Res. 2018;161:580-7.

42. Liu X, Lessner L, Carpenter DO. Association between residential proximity to fuelfired power plants and hospitalization rate for respiratory diseases. Environ Health Perspect. 2012;120:807-10.

43. Meng YY, Rull RP, Wilhelm M, Lombardi C, Balmes J, Ritz B. Outdoor air pollution and uncontrolled asthma in the San Joaquin Valley, California. J Epidemiol Community Health. 2010;64:142-7.

44. Choi G, Heo S, Lee J-T. Assessment of environmental injustice in Korea using synthetic air quality index and multiple indicators of socioeconomic status: a cross-sectional study. J Air Waste Manag Assoc. 2016;66:28-37.

45. Ma L-G, Chen Q-H, Wang Y-Y, Wang J, Ren Z-P, Cao Z-F, et al. Spatial pattern and variations in the prevalence of congenital heart disease in children aged 4-18 years in the Qinghai-Tibetan Plateau. Sci Total Environ. 2018;627:158-65.

46. Rible R, Aguilar E, Chen A, Bader JL, Goodyear-Moya L, Singh KT, et al. Exploration of spatial patterns of congenital anomalies in Los Angeles County using the vital statistics birth master file. Environ Monit Assess. 2018;190:184.

47. Odoh C, Sears CG, Tompkins LK, Hagemeyer AN, Pfeiffer JA, Polivka BJ, et al. Recruitment strategies and challenges: Lessons learned from a coal ash and children's health study. Res Nurs Health. 2019;42:446-57.

48. Louisville Gas and Electric Neighbor to Neighbor. https://lge-kucom/sites/default/ files/documents/LGE_Neighbor_to_Neighbor_Newsletter_Fall2012pdf. 2012.

49. United States Environmental Protection Agency Fact Sheet: Coal combustion residuals (CCR) surface impoundments with high hazard potential ratings EPA Publication 2009; No. EPA530-F-09-006.

50. Mill Creek Generating Station. In, 2020.

51. Bowers R, Cormier S. Dam Safety Assessment Report of CCW Impoundments LG\&E Mill Creek Station. US EPA Archive Document. 2009.

52. Allpress JLE, Curry RJ, Hanchette CL, Phillips MJ, Wilcosky TCA. GIS-based method for household recruitment in a prospective pesticide exposure study. Int J Health Geogr. 2008;7:18

53. U.S. Census Bureau. American Community Survey (ACS) Data. 2015

54. Sears CG, Zierold KM. Health of children living near coal ash. Glob Pediatr Health. 2017:4:1-8.

55. Zierold KM, Sears CG. Community views about the health and exposure of children living near a coal ash storage site. J Community Health. 2015;40:357-63.

56. McKenzie LM, Guo R, Witter RZ, Savitz DA, Newman LS, Adgate JL. Birth outcomes and maternal residential proximity to natural gas development in rural Colorado. Environ Health Perspect. 2014;122:412.

57. Whitworth KW, Marshall AK, Symanski E. Maternal residential proximity to unconventional gas development and perinatal outcomes among a diverse urban population in Texas. PLOS ONE. 2017;12:e0180966.

58. Gass K, Balachandran S, Chang HH, Russell AG, Strickland MJ. Ensemble-based source apportionment of fine particulate matter and emergency department visits for pediatric asthma. Am J Epidemiol. 2015;181:504-12.
59. Leung DYC. Outdoor-indoor air pollution in urban environment: challenges and opportunity. Front Environ Sci. 2015; 2.

60. Cyrys J, Pitz M, Bischof W, Wichmann HE, Heinrich J. Relationship between indoor and outdoor levels of fine particle mass, particle number concentrations and black smoke under different ventilation conditions. J Exposure Sci Environ Epidemiol. 2004;14:275-83.

61. Nadali A, Arfaeinia $H$, Asadgol Z, Fahiminia M. Indoor and outdoor concentration of PM10, PM2.5 and PM1 in residential building and evaluation of negative air ions (NAls) in indoor PM removal. Environ Pollut Bioavailab. 2020;32:47-55.

62. US EPA. Indoor Air Quality. In.

63. Achenbach T, Rescorla L. Manual for the ASEBA school-age forms \& profiles: an integrated system of multi-informant assessment Burlington, VT: University of Vermont. Research Center for Children, Youth, \& Families 2001; 1617.

64. Alotaibi R, Bechle M, Marshall JD, Ramani T, Zietsman J, Nieuwenhuijsen MJ, et al. Traffic-related air pollution and the burden of childhood asthma in the contiguous United States in 2000 and 2010. Environ Int. 2019;127:858-67.

65. Wang S, Zhang J, Zeng X, Zeng Y, Wang S, Chen S. Association of traffic-related air pollution with children's neurobehavioral functions in Quanzhou, China. Environ Health Perspect. 2009;117:1612-8.

66. Nasari MM, Szyszkowicz M, Chen H, Crouse D, Turner MC, Jerrett $M$, et al. A class of non-linear exposure-response models suitable for health impact assessment applicable to large cohort studies of ambient air pollution. Air Qual Atmos Health. 2016;9:961-72.

67. Pappin A, Crouse D, Christidis T, Erickson A, Pinault L, Weichenthal S, et al. Nonlinear associations between low levels of fine particulate matter and mortality across three cycles of the Canadian Census Health and Environment Cohort. Environ Epidemiol. 2019; 3.

68. Scott LM, Janikas MV. Spatial statistics in ArcGIS. In: Handbook of applied spatial analysis. Springer, 2010, pp 27-41.

69. Anselin L. Local indicators of spatial association-LISA. Geogr Anal. 1995;27:93-115.

70. Odoi A, Busingye D. Neighborhood geographic disparities in heart attack and stroke mortality: comparison of global and local modeling approaches. Spat Spatio-Temporal Epidemiol. 2014;11:109-23.

71. Fisher JB, Kelly M, Romm J. Scales of environmental justice: combining GIS and spatial analysis for air toxics in West Oakland, California. Health Place. 2006;12:701-14.

72. Sunyer J, Esnaola M, Alvarez-Pedrerol M, Forns J, Rivas I, López-Vicente $M$, et al. Association between traffic-related air pollution in schools and cognitive development in primary school children: a prospective cohort study. PLoS Med. 2015;12:e1001792.

73. Suades-González E, Gascon M, Guxens M, Sunyer J. Air pollution and neuropsychological development: a review of the latest evidence. Endocrinology. 2015;156:3473-82.

74. McConaughy SH. Using the child behavior checklist and related instruments in school-based assessment of children. Sch Psychol Rev. 1985;14:479-94.

75. Bartov G, Deonarine A, Johnson TM, Ruhl L, Vengosh A, Hsu-Kim H. Environmental impacts of the Tennessee Valley Authority Kingston coal ash spill. 1. Source apportionment using mercury stable isotopes. Environ Sci Technol. 2013;47:2092-9.

76. Godoy MLD, Godoy JM, Artaxo P. Aerosol source apportionment around a large coal fired power plant-thermoelectric Complex Jorge Lacerda, Santa Catarina, Brazil. Atmos Environ. 2005:39:5307-24.

77. Tran NQV, Miyake K. Neurodevelopmental disorders and environmental toxicants: epigenetics as an underlying mechanism. Int J Genom. 2017;2017:7526592.

78. Dunn GA, Nigg JT, Sullivan EL. Neuroinflammation as a risk factor for attention deficit hyperactivity disorder. Pharmacol Biochem Behav. 2019;182:22-34.

79. Juda-Rezler K, Kowalczyk D. Size distribution and trace elements contents of coal fly ash from pulverized boilers. Pol J Environ Stud. 2013;22:25-40.

80. Medina A, Gamero P, Querol X, Moreno N, De León B, Almanza M, et al. Fly ash from a Mexican mineral coal I: mineralogical and chemical characterization. J Hazard Mater. 2010;181:82-90.

\section{ACKNOWLEDGEMENTS}

The authors would like to acknowledge and thank Abby Hagemeyer, Lindsay Tompkins, Chisom Odoh, Jack Pfeiffer, Carol Norton, Jillian Winn, and Paula Kingsolver for their assistance with data collection. We would like to thank the community and community leaders for their participation in this study. In addition, the authors would like to acknowledge C. Hanchette (deceased, October 2017) for her contributions to the overall study.

\section{FUNDING}

This research was supported by the National Institutes of Health, National Institute of Environmental Health Sciences (Grant/Award Number: R01ES024757, PI: Zierold). The 
134

funding agency did not have a role in the design of the study, in collection, analysis, or interpretation of the data, in the writing of the report, or in the decision to submit the article for publication.

\section{ETHICS APPROVAL}

This study was approved by the Institutional Review Boards of the University of Louisville (\#14.1069) and the University of Alabama at Birmingham (\#300003807).

\section{COMPETING INTERESTS}

The authors declare no competing interests.

\section{ADDITIONAL INFORMATION}

Supplementary information The online version contains supplementary material available at https://doi.org/10.1038/s41370-021-00369-7.

Correspondence and requests for materials should be addressed to K.M.Z.

Reprints and permission information is available at http://www.nature.com/ reprints

Publisher's note Springer Nature remains neutral with regard to jurisdictional claims in published maps and institutional affiliations. 